\title{
Article \\ Process Optimization of Amorphous Carbon Hard Mask in Advanced 3D-NAND Flash Memory Applications
}

\author{
Zheng Jiang, Hao Zhu and Qingqing Sun *
}

State Key Laboratory of ASIC and System, School of Microelectronics, Fudan University, Shanghai 200433, China; 18112020025@fudan.edu.cn (Z.J.); hao_zhu@fudan.edu.cn (H.Z.)

* Correspondence: qqsun@fudan.edu.cn; Tel.: +86-21-6564-7395

Citation: Jiang, Z.; Zhu, H.; Sun, Q. Process Optimization of Amorphous Carbon Hard Mask in Advanced 3D-NAND Flash Memory Applications. Electronics 2021, 10, 1374. https://doi.org/10.3390/ electronics10121374

Academic Editor: Antonio Di Bartolomeo

Received: 12 May 2021

Accepted: 5 June 2021

Published: 8 June 2021

Publisher's Note: MDPI stays neutral with regard to jurisdictional claims in published maps and institutional affiliations.

Copyright: (c) 2021 by the authors. Licensee MDPI, Basel, Switzerland. This article is an open access article distributed under the terms and conditions of the Creative Commons Attribution (CC BY) license (https:/ / creativecommons.org/licenses/by/ $4.0 /)$.

\begin{abstract}
Amorphous carbon hard mask (ACHM) films are widely used as etching hard masks in 3D-NAND flash memory, which has put forward higher requirements in the film deposition rate, film transparency, uniformity, and selective etching. In this work, the ACHM film processing is engineered and optimized by comparatively studying acetylene $\left(\mathrm{C}_{2} \mathrm{H}_{2}\right)$ and propylene $\left(\mathrm{C}_{3} \mathrm{H}_{6}\right)$ as carbon sources at the different temperatures of $300{ }^{\circ} \mathrm{C}, 350{ }^{\circ} \mathrm{C}$ and $400{ }^{\circ} \mathrm{C}$. By increasing the deposition temperature, the deposition rate, non-uniformity, and dry etch rate of ACHM are improved at the penalty of a slightly increased extinction coefficient of the film, due to lower incorporation of hydrocarbon reactants absorbed into film at higher temperatures. However, the Fourier transformation infrared (FTIR) spectrum intensity is decreased with the increase of the deposition temperature. The lower dry etch rate of $\mathrm{ACHM}$ is achieved by using $\mathrm{C}_{3} \mathrm{H}_{6}$ as a carbon source deposited at $400{ }^{\circ} \mathrm{C}$. The best dry etch selective ratio values are also achieved with 10.9 and 9.5 for $\mathrm{SiO}_{2}$ and $\mathrm{SiN}$, respectively. These experimental results can be very promising in the advancement of etching process in 3D-NAND applications.
\end{abstract}

Keywords: dry etch; PECVD; hard mask; ACHM; 3D-NAND

\section{Introduction}

The exponential growth of mobile electronic devices like smartphones and fitness trackers has urged great demands for high performance and high density memory. A three-dimensional type of NAND (3D-NAND) flash memory is thus developed, improving the data storage density per area through scaling down and vertical integration [1-3]. For 3D-NAND, one of the key challenges is the requirement of a hard mask (HM) with better transparency and a higher etch selective ratio in lithograph and dry etch process due to a high aspect ratio pattern (HARP) [4-6]. Deeper and narrower trench etching is required due to more $\mathrm{SiO}_{2} / \mathrm{SiN}$ or $\mathrm{SiO}_{2} /$ Poly storage layers. Moreover, mask shift or deformation can cause leakage degrading refresh time when the aspect ratio gets higher. A thickness-limited photoresist (PR) and a poor dry etch HM are challenging for these requirements. The thinner PRs will result in pattern bending or collapse-wiggling in the etch process [7-9]. In recent years, amorphous carbon hard masks (ACHM) have been used in semiconductor device fabrication, replacing the conventional $\mathrm{SiO}_{2}$ or $\mathrm{Si}_{3} \mathrm{~N}_{4} \mathrm{HM}$ due to its robust film properties such as high transparency, high etch selectivity, high durability for plasma Asher and easy elimination by oxygen $\left(\mathrm{O}_{2}\right)$ plasma [10-12]. ACHM is characterized by an intermediate $\mathrm{H}$ content to amorphous carbon with sp2-bonded clusters, interconnected by a random network of sp3-bonded atomic sites. The properties of such coatings are directly related to the hybridization state of carbon bonds and the hydrogen content [13-16]. ACHM can be deposited by plasma-enhanced chemical vapor deposition (PECVD) with various carbon sources, such as methane $\left(\mathrm{CH}_{4}\right)$, acetylene $\left(\mathrm{C}_{2} \mathrm{H}_{2}\right)$, propylene $\left(\mathrm{C}_{3} \mathrm{H}_{6}\right)$ and 1-hexene $\left(\mathrm{C}_{6} \mathrm{H}_{12}\right)$ [17-19]. However, an experimental study comparing the film deposition, dry etch characteristics and approaches for higher selective ratios by using different precursors have been rarely reported. 
In this work, we use $\mathrm{C}_{2} \mathrm{H}_{2}$ and $\mathrm{C}_{3} \mathrm{H}_{6}$ as carbon sources which are popularly used in mass production to compare the deposition rate, uniformity, extinction coefficient, Fourier transform infrared (FTIR) spectra and dry etch rate. By characterizing the selective ratio of $\mathrm{ACHM}$ to $\mathrm{SiO}_{2}$ and $\mathrm{SiN}$, the optimum etching parameters of ACHMs with maximum selective ratio to $\mathrm{SiO}_{2}$ and $\mathrm{SiN}$ are obtained.

\section{Materials and Methods}

ACHM films ( $350 \mathrm{~nm}$ ) were deposited on a p-type Si-substrate in a $300 \mathrm{~mm}$ standard PECVD system by using $\mathrm{C}_{2} \mathrm{H}_{2}$ and $\mathrm{C}_{3} \mathrm{H}_{6}$ as carbon sources. Wafers were cleaned in diluted $\mathrm{HF}$ and $\mathrm{SC}_{1}$ solutions in sequence. After cleaning, the wafer was loaded into the reactor with CCP (capacitive coupled plasma). RF power of $1000 \mathrm{~W}$ and a reactor pressure of 5 torr were used. The flow rates of $\mathrm{C}_{2} \mathrm{H}_{2}$ and $\mathrm{C}_{3} \mathrm{H}_{6}$ were both $1500 \mathrm{sccm}$. Different deposition temperatures of $300{ }^{\circ} \mathrm{C}, 350{ }^{\circ} \mathrm{C}$ and $400{ }^{\circ} \mathrm{C}$ were tested, and the deposition rate, film uniformity, extinction coefficient and dry etch rate were measured by a KLA-Tencor Aleris 8500 Spectroscopic Ellipsometry. Chemical structure and $\mathrm{C}-\mathrm{H}$ bonding was measured by FTIR spectroscopy. The thickness of the film was measured at 49 different points selected from the $300 \mathrm{~mm}$ wafer. The deposition film was etched using $\mathrm{O}_{2}$ plasma and mixed $\mathrm{CF}_{4}$ and $\mathrm{CHF}_{3}$. The film thickness was measured after each deposition and etch process, and the dry etch selectivity was further calculated by $\mathrm{T}_{\mathrm{SiN} / \mathrm{SiO} 2} / \mathrm{T}_{\mathrm{ACHM}}$, where $\mathrm{T}_{\mathrm{SiN} / \mathrm{SiO} 2}$ and $\mathrm{T}_{\mathrm{ACHM}}$ are the thickness of $\mathrm{SiN}$ or $\mathrm{SiO}_{2}$ and $\mathrm{ACHM}$ removed by chemical gas.

\section{Results}

Figure 1 shows the dependence of the deposition rate and non-uniformity on the deposition temperature by using $\mathrm{C}_{2} \mathrm{H}_{2}$ and $\mathrm{C}_{3} \mathrm{H}_{6}$ precursors. From Figure $1 \mathrm{a}$, the deposition rate with $\mathrm{C}_{2} \mathrm{H}_{2}$ decreased from $6018 \AA /$ min to $4941 \AA /$ min when increasing the deposition temperature from $300{ }^{\circ} \mathrm{C}$ to $400{ }^{\circ} \mathrm{C}$. Similar trend is observed for the test using $\mathrm{C}_{3} \mathrm{H}_{6}$ (decreased from $6081 \AA / \mathrm{min}$ to $5036 \AA / \mathrm{min}$ ). Such dependence of the deposition rate on temperature is because of a lower incorporation of hydrocarbon reactants absorbed into the film at higher temperatures based on the absorbed layer model; the erosion process also became stronger at higher temperatures, leading to a lower deposition rate [20]. Figure $1 \mathrm{~b}$ clearly suggests that the film non-uniformity is improved from $4.5 \%$ to $2.1 \%$ for $\mathrm{C}_{2} \mathrm{H}_{2}$, and from $3.5 \%$ to $1.96 \%$ for $\mathrm{C}_{3} \mathrm{H}_{6}$ when increasing temperature from $300{ }^{\circ} \mathrm{C}$ to $400{ }^{\circ} \mathrm{C}$. This is also due to the lower incorporation of hydrocarbon reactants into film at elevated temperatures [21]. It should also be noted that increasing the substrate temperature is also beneficial to the compensation of the dangling bonds on the surface of the film, which further reduces the defects in the film and enhances the film density.
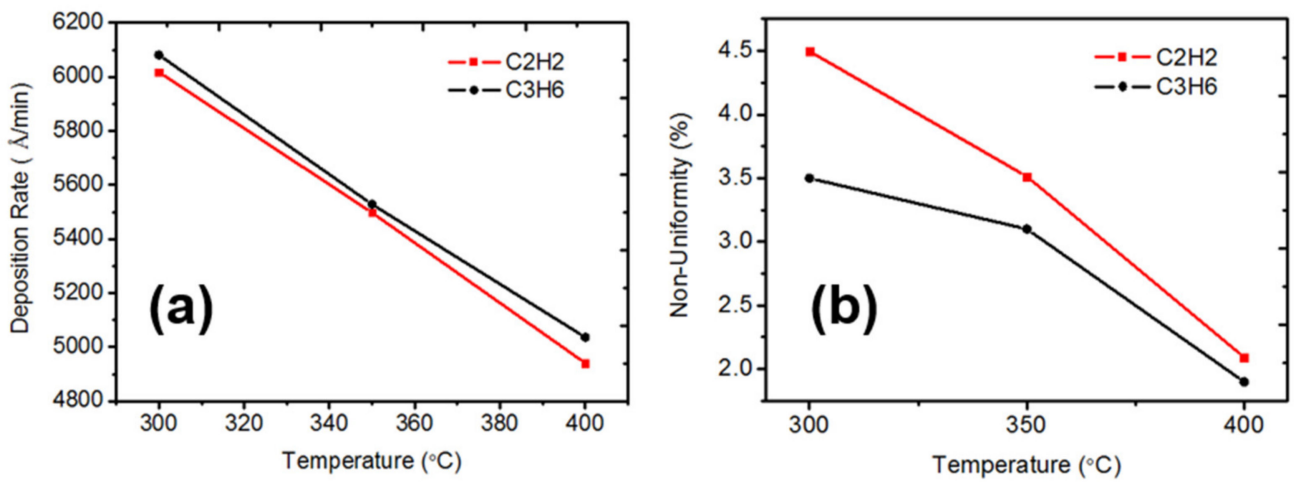

Figure 1. The profile of (a) deposition rate and (b) non-uniformity with the increase of deposition temperature.

The extinction coefficient (EC) represents the capability of a chemical species or substance to absorb light at a particular wavelength. For HM applications, low EC values are typically required in 3D-NAND $\left(<0.5\right.$ at $\left.300{ }^{\circ} \mathrm{C} \sim 400{ }^{\circ} \mathrm{C}\right)$. Figure 2 shows the EC 
measured as a function of deposition temperature to study film optical characteristics. By increasing the temperature from $300{ }^{\circ} \mathrm{C}$ to $400{ }^{\circ} \mathrm{C}$, the EC of ACHM film deposited with $\mathrm{C}_{2} \mathrm{H}_{2}$ was increased from 0.384 to 0.430 and the film using $\mathrm{C}_{3} \mathrm{H}_{6}$ was increased from 0.379 to 0.421. Such an increase in EC with increasing temperature is attributed to the increase of sp2 $\mathrm{C}-\mathrm{H}$ bonds portion. According to the subplantation model, a higher temperature is favorable for the development of sp2 C-H bonds [22]. The sp2 chemical bonds are similar to graphite and can block more light.

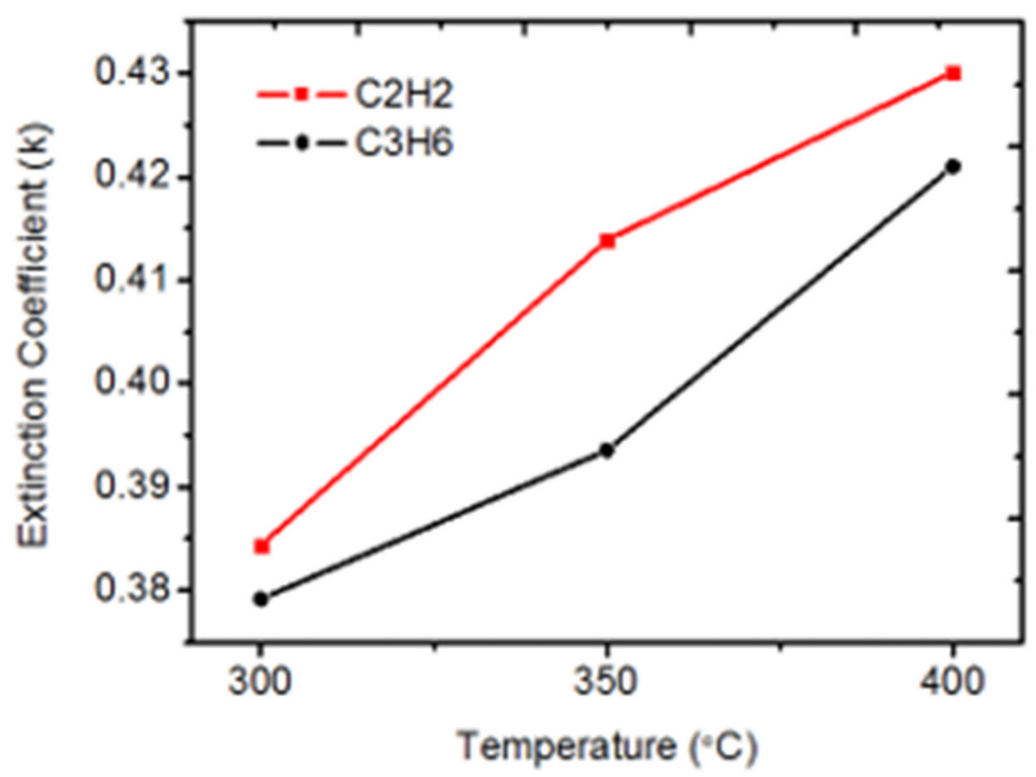

Figure 2. The profile of the extinction coefficient as a function of deposition temperature.

It is known that there are three main absorption bands for ACHM film located at $2870 \mathrm{~cm}^{-1}, 2930 \mathrm{~cm}^{-1}$, and $2955 \mathrm{~cm}^{-1}$, respectively. Hydrocarbons observed at $2870 \mathrm{~cm}^{-1}$ are attributed to the $\mathrm{sp}^{3}-\mathrm{CH}_{3}$ symmetric/C-H symmetric stretching mode. Hydrocarbons observed at $2930 \mathrm{~cm}^{-1}$ and $2955 \mathrm{~cm}^{-1}$ are ascribed to the $\mathrm{sp}^{3}-\mathrm{CH}_{2}$ and $\mathrm{sp}^{3}-\mathrm{CH}_{3}$ asymmetric $\mathrm{C}-\mathrm{H}$ stretching mode, respectively. As shown in Figure 3, the absorption peak intensity of these bands decreases with increasing deposition temperature, but the curve profiles exhibit similar behavior. These spectra absorption results indicated that ACHM film has a lower content of $\mathrm{C}-\mathrm{H}$ bonds at higher temperatures for both $\mathrm{C}_{2} \mathrm{H}_{2}$ and $\mathrm{C}_{3} \mathrm{H}_{6}$, which is due to the decrease of the sticking coefficient of hydrocarbon content, with an increase of deposition temperature [23]. By comparing the spectra obtained from the films using different precursors, the ACHM film using $\mathrm{C}_{2} \mathrm{H}_{2}$ illustrates relatively higher absorption intensity at all tested temperatures, which can be explained by the lower number of $\mathrm{sp}^{3}-\mathrm{CH}_{2}$ of the $\mathrm{C}_{2} \mathrm{H}_{2}$ film at $2930 \mathrm{~cm}^{-1}$ than that of the $\mathrm{C}_{3} \mathrm{H}_{6}$ film [24].
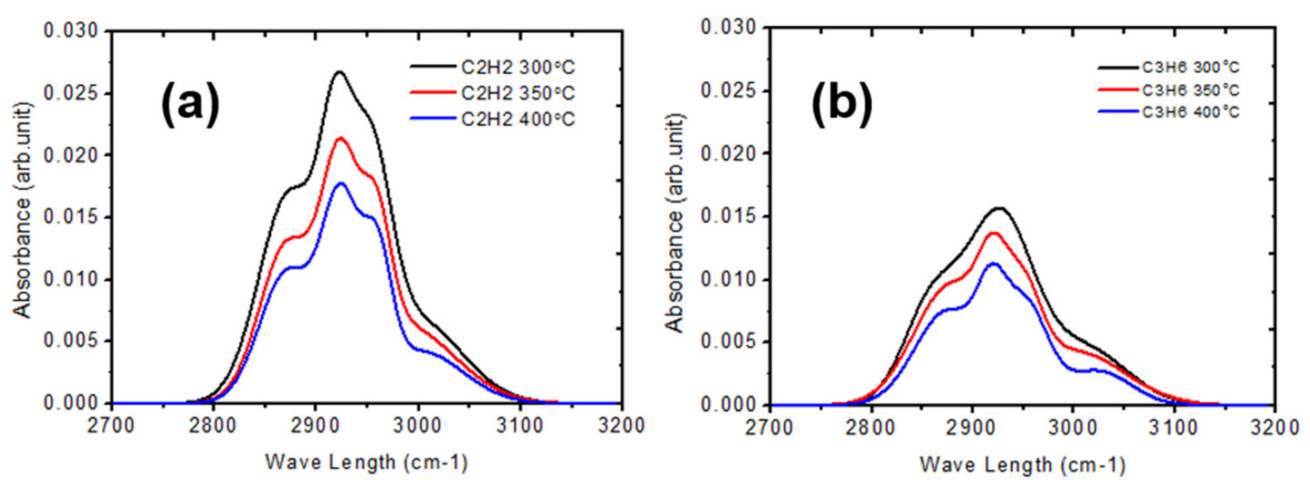

Figure 3. FTIR spectra of ACHM with different source of (a) $\mathrm{C}_{2} \mathrm{H}_{2}$ and (b) $\mathrm{C}_{3} \mathrm{H}_{6}$ at $300{ }^{\circ} \mathrm{C}, 350{ }^{\circ} \mathrm{C}$ and $400{ }^{\circ} \mathrm{C}$. 
Figure 4 shows the dry etch rate of ACHM film as a function of deposition temperature. Lower etch rate is observed at a higher temperature for both films. Similarly, this is because of the lower incorporation of hydrocarbon and absorption reactants of atomic hydrogen in the surface at higher temperatures. More ions with sufficient energy will migrate resulting in a denser film, and thus a lower dry etch rate [25]. Figure 5a,b show the dry etch rate mapping at $400{ }^{\circ} \mathrm{C}$ of the film using $\mathrm{C}_{2} \mathrm{H}_{2}$ and $\mathrm{C}_{3} \mathrm{H}_{6}$, respectively. The 3-sigma value of etch rate with $\mathrm{C}_{3} \mathrm{H}_{6}$ was $6.37 \%$, and the value was $7.40 \%$ with $\mathrm{C}_{2} \mathrm{H}_{2}$, which was slightly higher than $\mathrm{C}_{3} \mathrm{H}_{6}$. This suggests that $\mathrm{ACHM}$ with $\mathrm{C}_{3} \mathrm{H}_{6}$ had better uniformity and lower etch rate variation, which are critical factors considering practical applications in 3D-NAND fabrication process [19].

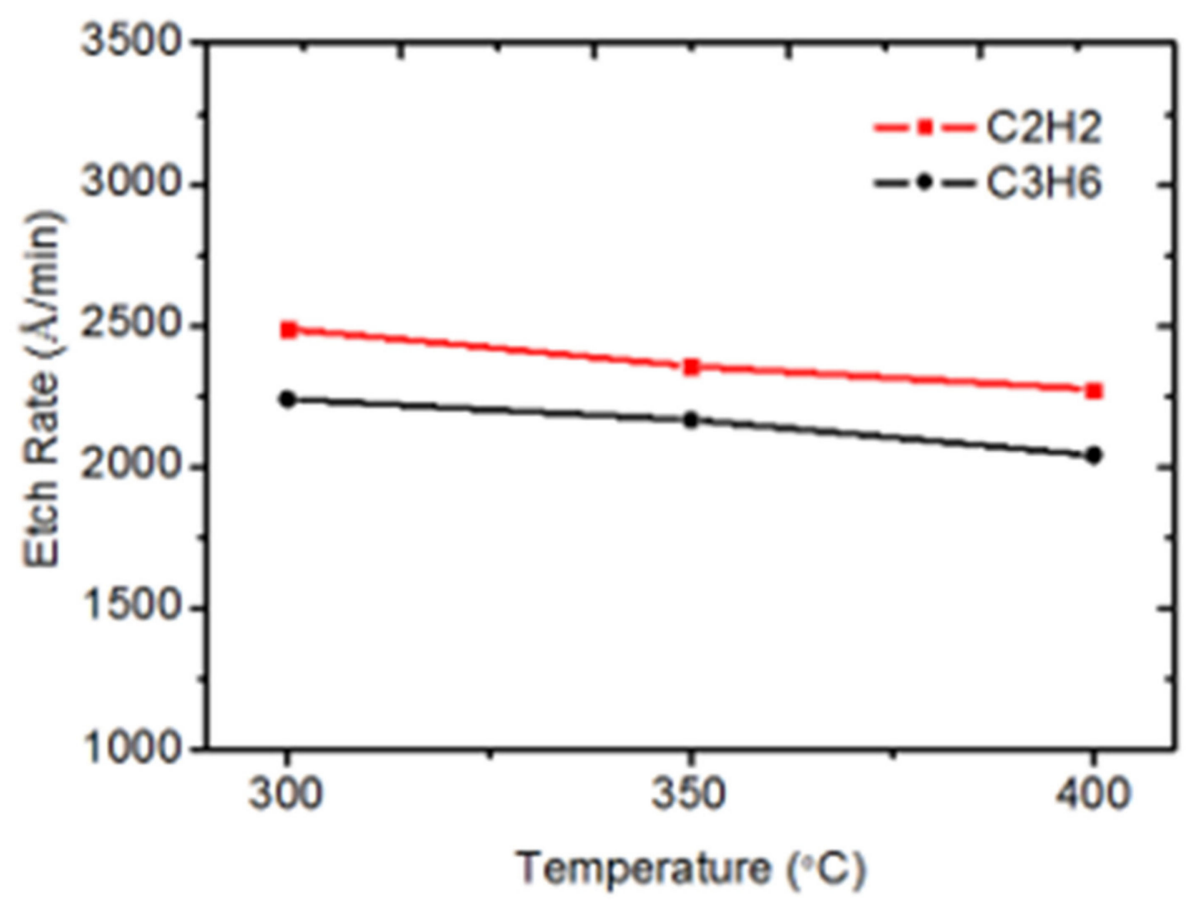

Figure 4. Dry etch rate as a function of deposition temperature.

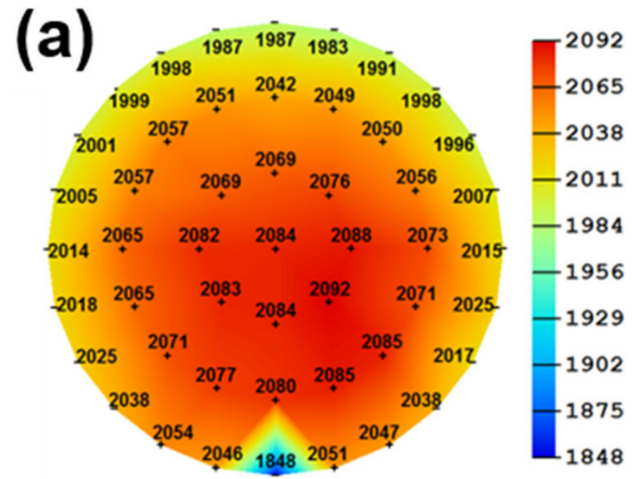

Avg: 2039.78

1Sig: $2.12 \%$

3Sig: $6.37 \%$

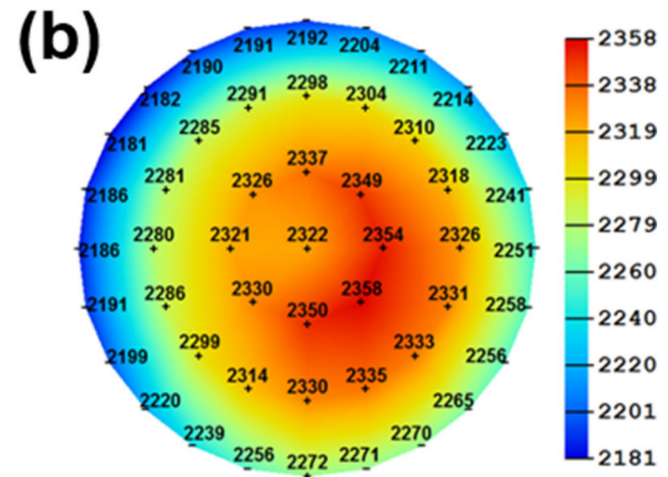

Avg: 2271.78

1Sig: $2.47 \%$

3Sig: $\mathbf{7 . 4 0} \%$

Figure 5. Dry etch rate map of the film using (a) $\mathrm{C}_{3} \mathrm{H}_{6}$ and (b) $\mathrm{C}_{2} \mathrm{H}_{2}$ at $400{ }^{\circ} \mathrm{C}$.

From the above results, higher temperatures will decrease the non-uniformity and etch rate, which were considered more important as a dry etch hard mask in 3D-NAND application due to the direct impact on yield data and process cost. Compared to $\mathrm{C}_{2} \mathrm{H}_{2}$, 
using $\mathrm{C}_{3} \mathrm{H}_{6}$ as a carbon source will increase the deposition rate from $4941 \AA$ / min to $5036 \AA / \mathrm{min}$, and decrease the non-uniformity from $2.1 \%$ to $1.96 \%$. The dry etch rate is also decreased from $2271.78 \AA / \mathrm{min}$ to $2039.78 \AA / \mathrm{min}$ as shown in Figure 5. Although the EC is increased to 0.421 for the $\mathrm{C}_{3} \mathrm{H}_{6}$ precursor at a $400{ }^{\circ} \mathrm{C}$ deposition temperature, the value is sufficient for the requirement as a dry etch hard mask. It is easily concluded that the best condition for ACHM film processing with an optimized deposition rate, non-uniformity, $\mathrm{EC}$ and dry etch rate is by using $\mathrm{C}_{3} \mathrm{H}_{6}$ precursor and a $400{ }^{\circ} \mathrm{C}$ deposition temperature.

Finally, we compare the dry etch rates for $\mathrm{SiN}$ and $\mathrm{SiO}_{2}$ with $\mathrm{ACHM}$ by using a $\mathrm{C}_{3} \mathrm{H}_{6}$ precursor and a $400{ }^{\circ} \mathrm{C}$ deposition temperature for the purpose of verification of an effective etch hard mask. SiN and $\mathrm{SiO}_{2}$ are deposited at $400{ }^{\circ} \mathrm{C}$ by the same PECVD system. By calculating the dry etch selective ratio to $\mathrm{SiN}$ and $\mathrm{SiO}_{2}$ using the formular mentioned above, we have achieved the best dry etch selective ratio values of 10.9 and 9.5 for $\mathrm{SiO}_{2}$ and $\mathrm{SiN}$ at $90 \mathrm{~W}$ bias power and 0.125 torr pressure in the etch system (Figure 6). Such high etch selective ratios to $\mathrm{SiN}$ and $\mathrm{SiO}_{2}$ are very promising for practical application in 3D-NAND fabrication as dry etch hard masks. With the high etch selective ratio hard masks used in ploy gates and storage layers, it is possible to largely improve switching speed and storage intensity by scaling channel dimensions and increasing storage layers [26,27].

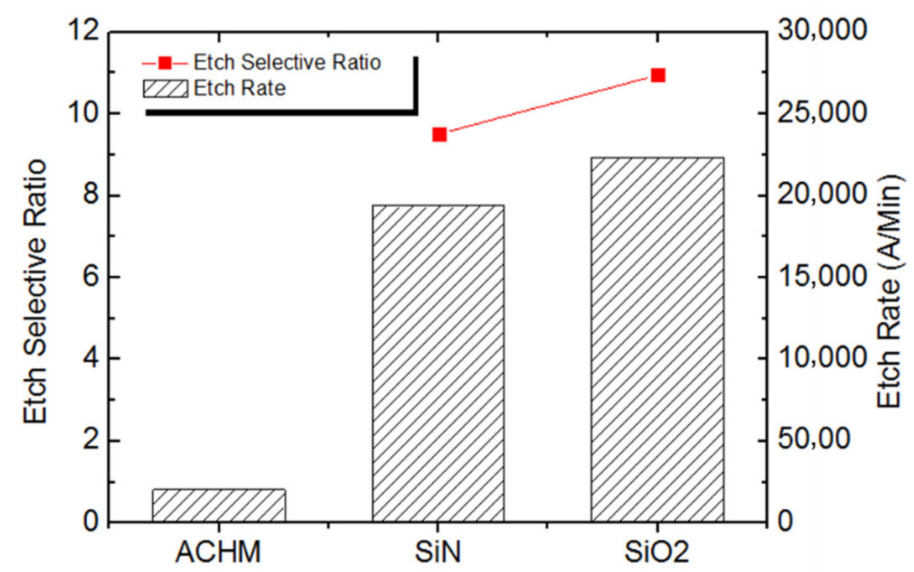

Figure 6. Etch Rate for $\mathrm{ACHM}, \mathrm{SiN}$ and $\mathrm{SiO}_{2}$, and the etch selective ratio to $\mathrm{SiN}$ and $\mathrm{SiO}_{2}$ at $400{ }^{\circ} \mathrm{C}$.

\section{Conclusions}

In summary, the deposition process and the ACHM film properties have been studied and compared by using different precursors in PECVD, and the deposition temperature is further optimized towards high-reliability film quality. The etch process and film properties are investigated, including the deposition temperature, film non-uniformity, etch rate and etch selective ratio to $\mathrm{SiN}$ and $\mathrm{SiO}_{2}$. A precursor/temperature co-optimization is developed which is effective in achieving sufficient etch selective ratio and film uniformity. Such process optimization can be very attractive in forming high-reliability ACHM in 3D-NAND fabrication process.

Author Contributions: Writing—Original Draft, Z.J.; Writing—Review \& Editing, H.Z.; Supervision, Q.S. All authors have read and agreed to the published version of the manuscript.

Funding: This work was supported by the National Key Research and Development Program of China (2018YFB2202800), the Program of Shanghai Subject Chief Scientist (18XD1402800) and the Support Plans for the Youth Top-Notch Talents of China.

Data Availability Statement: The data presented in this study are available on request from the corresponding author.

Conflicts of Interest: The authors declare no conflict of interest. 


\section{References}

1. Park, S.H.; Kim, Y.; Kim, W.; Seo, J.Y.; Park, B.-G. Vertical-Channel STacked ARray (VCSTAR) for 3D NAND flash memory. Solid-State Electron. 2012, 78, 34-38. [CrossRef]

2. Micheloni, R.; Crippa, L.; Zambelli, C.; Olivo, P. Architectural and Integration Options for 3D NAND Flash Memories. Computers 2017, 6, 27. [CrossRef]

3. Kim, S.; Lee, S.H.; Park, S.K.; Kim, Y.; Cho, S.; Park, B.G. Investigation of Retention Characteristics Caused by Charge Loss for Charge Trap NAND Flash Memory. J. Semicond. Technol. Sci. 2017, 17, 584-590. [CrossRef]

4. Pauliac-Vaujour, S.; Brianceau, P.; Comboroure, C.; Faynot, O. Improvement of high resolution lithography by using amorphous carbon hard mask. Microelectron. Eng. 2008, 85, 800-804. [CrossRef]

5. Ho, C.Y.; Lin, X.J.; Chien, H.R.; Lien, C. High aspect ratio contact hole etching using relatively transparent amorpgous carbon hard mask deposition from propylene. Thin Solid Film. 2010, 518, 6076-6079. [CrossRef]

6. Lai, C.C.; Chang, Y.H.; Chien, H.J.; Lu, M.C. Hard mask and lithographic capabilities improvement by amorphous carbon step coverage optimization in high aspect ratio device pattern. Vacuum 2018, 153, 267-273. [CrossRef]

7. Lin, Y.-Y.; Chen, C.-C.; Li, C.-Y.; Wang, Z.-S.; Chen, C.-H. Pattern wiggling investigation of self-aligned double patterning for 2x nm node NAND Flash and beyond. In SPIE Advanced Lithography; SPIE: Washington, DC, USA, 2013.

8. Yu, B.-L.; Huang, Y.; Luo, S.-A.; Cheng, Y.-S.; Hung, Y.-T.; Luoh, T.; Yang, L.-W.; Yang, T.; Chen, K.-C. APF Hard Mask Distortion Improvement for High Aspect Ratio Patterning; Institute of Electrical and Electronics Engineers (IEEE): New York, NY, USA, 2015; pp. 1-3.

9. Negishi, N.; Takesue, H.; Sumiya, M.; Yoshida, T.; Momonoi, Y.; Izwa, M. Deposition control for reduction of $193 \mathrm{~nm}$ photoresist degradation in dielectric etching. J. Vac. Sci. Technol. B 2005, 23, 217-223. [CrossRef]

10. Lee, S.; Jung, D.; Yang, J.; Boo, J.-H.; Kim, H.; Lee, J.; Chae, H. Characterization of oxygen and nitrogen rapid thermal annealing processes for ultra-low-k SiCOH films. J. Mater. Res. 2008, 23, 856-861. [CrossRef]

11. Kaspar, P.; Jeyaram, Y.; Jäckel, H.; Foelske, A.; Kötz, R.; Bellini, S. Silicon nitride hardmask fabrication using cyclic CHF3-base reactive ion etching process for vertical profile nanostructure. J. Vaccum Sci. Technol. B 2010, 28, 1179-1186. [CrossRef]

12. Liu, Z.; Shah, A.; Alasaarela, T.; Chekurov, N.; Savin, H.; Tittonen, I. Silicon dioxide mask by plasma enhanced atomic layer deposition in focused ion beam lithography. Nanotechnology 2017, 28, 085303. [CrossRef]

13. Buijnsters, J.; Fernandez, R.G.; Jiménez, I.; Camero, M.; Agulló-Rueda, F.; Gómez-Aleixandre, C. Hydrogen quantification in hydrogenated amorphous carbon films by infrared, Raman, and x-ray absorption near edge spectroscopies. J. Appl. Phys. 2009, 105, 93510. [CrossRef]

14. Ahmad, I.; Roy, S.; Rahman, A.; Okpalugo, T.; Maguire, P.; McLaughlin, J. Substrate effects on the microstructure of hydrogenated amorphous carbon films. Curr. Appl. Phys. 2009, 9, 937-942. [CrossRef]

15. Durand-Drouhin, O.; Lejeune, M.; Benlahsen, M. Growth and bonding structure of hard hydrogenated amorphous carbon thin films deposited from an electron cyclotron resonance plasma. J. Appl. Phys. 2002, 91, 867. [CrossRef]

16. Davis, C.A.; Knowles, M.; Amaratunga, G. Cross-sectional structure of tetrahedral amorphous carbon thin films. Surf. Coat. Technol 1995, 76, 316-321. [CrossRef]

17. Kim, J.K.; Cho, S.I.; Kim, N.G.; Jhon, M.S.; Min, K.S.; Kim, C.K.; Yeom, G.Y. Study on the etching characteristics of amorphous carbon layer in oxygen plasma with carbonyl sulfide. J. Vac. Sci. Technol. A 2013, 31, 021301. [CrossRef]

18. Lee, S.; Won, J.; Choi, J.; Park, J.; Jee, Y.; Lee, H.; Byun, D. Comparative study on the properties of amorphous carbon layers deposited from 1-hexene and propylene for dry etch hard mask application in semiconductor device manufacturing. Thin Solid Film. 2011, 519, 6683-6687. [CrossRef]

19. Lee, S.; Won, J.; Choi, J.; Jang, S.; Jee, Y.; Lee, H.; Byun, D. Preparation and analysis of amorphous carbon films deposited from $(\mathrm{C} 6 \mathrm{H} 12) / \mathrm{Ar} / \mathrm{He}$ chemistry for application as the dry etch hard mask in the semiconductor manufacturing process. Thin Solid Film. 2011, 519, 6737-6740. [CrossRef]

20. Piazza, F.; Grambole, D.; Schneider, D.; Casiraghi, C.; Ferrari, A.; Robertson, J. Protective diamond-like carbon coatings for future optical storage disks. Diam. Relat. Mater. 2005, 14, 994-999. [CrossRef]

21. Von Keudell, A.; Jacob, W. Surface relaxation during plasma-enhanced chemical vapor deposition of hydrocarbon films, investigated by in situ ellipsometry. Appl. Phys. 1997, 81, 1531. [CrossRef]

22. Hayashi, Y.; Hagimoto, K.; Ebisu, H.; Kalaga, M.K.; Soga, T.; Umeno, M.; Jimbo, T. Effect of Radio Frequency Power on the Properties of Hydrogenated Amorphous Carbon Films Grown by Radio Frequency Plasma-Enhanced Chemical Vapor Deposition. Jpn. J. Appl. Phys. 2000, 39, 4088-4093. [CrossRef]

23. Von Keudell, A. Formation of polymer-like hydrocarbon films from radical beams of methyl and atomic hydrogen. Thin Solid Film. 2002, 402, 1-37. [CrossRef]

24. Lai, C.C.; Chang, Y.H.; Chien, H.J.; Lu, M.C. Amorphous carbon process optimization to increase hard mask and lithographic capabilities by its step coverage improvement. In Proceedings of the 2017 6th International Symposium on Next Generation Electronics (ISNE), Keelung, Taiwan, 23-25 May 2017.

25. Padhi, D.; Kim, B.H.; Witty, D. Dry etch selectivity of a-C:H hardmasks for sub-65 nm patterning applications. J. Vac. Sci. Technol. B Microelectron. Nanometer Struct. 2009, 27, 1809. [CrossRef]

26. Regine, R. Non-equilibrium polaritonics - non-linear effects and optical switching. Ann. Phys. 2013, 525, 66-73.

27. Lubatsch, A.; Frank, R. Behavior of Floquet Topological Quantum States in Optically Driven Semiconductors. Symmetry 2019, 11, 1246. [CrossRef] 